\title{
Glycine and $\mathrm{Na}^{+}$transport in preimplantation mouse embryos*
}

\author{
J. G. Hobbs and P. L. Kaye \\ Department of Physiology and Pharmacology, University of Queensland, St Lucia, Queensland 4067, \\ Australia
}

\begin{abstract}
Summary. The dependence of glycine uptake on glycine and $\mathrm{Na}^{+}$concentrations was determined and compared in 2-cell embryos and blastocysts. In both, uptake was by a combination of a $\mathrm{Na}^{+}$-independent non-saturable route and $\mathrm{a} \mathrm{Na}^{+}$-dependent saturable system with $K_{\mathrm{m}}$ values of $62 \mu \mathrm{M}$ and $274 \mu \mathrm{M}$ for 2-cell embryos and blastocysts respectively. $\mathrm{Na}^{+}$-dependent saturable uptake by embryos of both stages had a Hill coefficient of 2 for $\mathrm{Na}^{+}$, indicating co-transport of $2 \mathrm{Na}^{+}$with each glycine molecule. These results suggest that glycine enters 2-cell embryos by the $g l y$-system, and blastocysts by a similarly $\mathrm{Na}^{+}$-dependent system with characteristics resembling the A-system.
\end{abstract}

\section{Introduction}

Transport of zwitterionic amino acids into preimplantation mouse embryos occurs by at least three separate transport systems. A $\mathrm{Na}^{+}$-independent $\mathrm{L}$-system with strong exchange properties and preference for amino acids with polar branched side chains is present in mouse oocytes and all preimplantation stages examined (Holmberg \& Johnson, 1979; Kaye, Schultz, Johnson, Pratt \& Church, 1982; Colonna, Cecconi, Buccione \& Mangia, 1983). At about the time of compaction a $\mathrm{Na}^{+}$-dependent A-system appears which is strongly concentrative with preference for amino acids with small unbranched sidechains (Borland \& Tasca, 1974; Kaye et al., 1982). In addition to these, a glycine-specific $g l y$-system which requires $\mathrm{Na}^{+}$for maximum activity has been observed in pre-compaction embryos (Hobbs \& Kaye, 1985). This $g l y$-system has little exchange capacity, is strongly concentrative, transporting only glycine, and can be inhibited only by sarcosine. Whether or not it persists past compaction is not yet clear, since the A-system which appears at this time will transport glycine as well as alanine (DiZio \& Tasca, 1977), methionine and other amino acids (Kaye et al., 1982).

One of the differences between the $g l y$-system and the A-system in other tissues is the requirement for $\mathrm{Na}^{+}$. Vidaver (1964) showed that the $g l y$-system in pigeon red cells transports two $\mathrm{Na}^{+}$ for each glycine molecule, whereas in many other tissues the A-system appears to require only one $\mathrm{Na}^{+}$for uptake (Christensen, 1984). The requirement for two $\mathrm{Na}^{+}$has become an accepted discriminating feature of the $g l y$-system.

Since the supply of intracellular $\mathrm{Na}^{+}$to the juxtacoelic trophectodermal $\mathrm{Na}^{+}, \mathrm{K}^{+}$-ATPases could be important in blastocyst expansion by osmotic movement of $\mathrm{H}_{2} \mathrm{O}$ (Benos, Biggers, Balaban, Mills \& Overström, 1985), we have examined the $\mathrm{Na}^{+}$requirements of glycine transport in 2-cell embryos and blastocysts.

\footnotetext{
* Reprint requests to Dr P. L. Kaye.
} 


\section{Materials and Methods}

A complete description of the mice. superovulation and embryo collection techniques can be found in Hobbs \& Kaye (1985). Female Quackenbush mice 6-9 weeks of age were induced to superovulate by intraperitoneal injection of 10 i.u. PMSG (Folligon: Intervet (Aust) Pty Ltd, Artarmon, NSW, Australia) followed $44-50 \mathrm{~h}$ later by $10 \mathrm{i} . \mathrm{u}$. hCG (Chorulon: Intervet (Aust)) given between 09:00 and 12:00 h. They were inspected for vaginal plugs at 09:00 h. Two-cell embryos and blastocysts were flushed from the oviducts or uteri $48 \mathrm{~h}$ or $96 \mathrm{~h}$ after hCG injection respectively using Medium M2 modified to contain $0.33 \mathrm{~mm}$-sodium pyruvate, $5.6 \mathrm{~mm}$-glucose and $4 \mathrm{~g}$ bovine serum albumin/l (Hobbs \& Kaye, 1985). Incubations were carried out between 12:00 and 15:00 $\mathrm{h}$. Radioactive media $(1 \mu \mathrm{Ci} / \mu \mathrm{l})$ were prepared by adding medium, containing glycine at the appropriate concentration, to freeze-dried $\left[2-{ }^{3} \mathrm{H}\right]$ glycine supplied by Amersham (Aust) (Strawberry Hills, NSW, Australia) at about $12 \mathrm{Ci} / \mathrm{mmol}$. To measure glycine uptake, washed embryos were incubated in a $20-\mu 1$ droplet of radioactive medium under $4 \mathrm{ml}$ Silicone 200 fluid $\left(50 \mathrm{~mm}^{2} \mathrm{~s}^{-1}\right.$ : Dow Corning, Blacktown, NSW, Australia) on a heating block $\left(37^{\circ} \mathrm{C}\right)$.

$\mathrm{Na}^{+}$-free medium. Sodium-free $\mathrm{M} 2$ medium (M2- $\mathrm{Na}^{+}$) was prepared by replacing $\mathrm{NaCl}$ and sodium lactate equimolarly with choline chloride ( 3 times crystallized; Sigma Product No. C7017) and $\mathrm{NaHCO}_{3}$ with $\mathrm{KHCO}_{3}$. The Hepes ( $N$-2-hydroxyethyl piperazine- $N$ '-2-ethane sulphonic acid) used to buffer this medium was adjusted to $\mathrm{pH} 7.4$ with $\mathrm{KOH}$. The only $\mathrm{Na}^{+}$in the medium was derived from the $0.33 \mathrm{~mm}$-sodium pyruvate and glassware and was considered negligible in comparison to the $105 \mathrm{mM} \mathrm{Na}{ }^{+}$in Medium M2-lactate (see below). Glycine uptake measurements in Medium M2- $\mathrm{Na}^{+}$at $37^{\circ} \mathrm{C}$ were indistinguishable from those measured earlier (Hobbs \& Kaye, 1985) in Medium M2 on ice. To achieve the required $\mathrm{Na}^{+}$concentrations, choline chloride was replaced by $\mathrm{NaCl}$. For controls in these experiments, because of the absence of lactate in Medium M2- $\mathrm{Na}^{+}$, Medium M2 was prepared with sodium lactate replaced equimolarly by choline chloride (M2-lactate). Preliminary experiments revealed that such replacement of lactate had no effect on $\left[{ }^{3} \mathrm{H}\right]$ glycine uptake rates by 2 -cell embryos or blastocysts measured over $10 \mathrm{~min}$ at $37^{\circ} \mathrm{C}$.

$\mathrm{Na}^{+}$-dependence of glycine uptake. Before measurement of $\left[{ }^{3} \mathrm{H}\right] \mathrm{glycine}$ uptake, embryos were washed twice in $2 \mathrm{ml}$ Medium $\mathrm{M} 2-\mathrm{Na}^{+}$with $\mathrm{Na}^{+}$added to the appropriate concentration and preincubated in this medium for $30 \mathrm{~min}$ at $22^{\circ} \mathrm{C}$ before transfer to the same medium containing $1 \mathrm{mM}-\left[{ }^{3} \mathrm{H}\right]$ glycine.

Glycine dependence of glycine uptake. Uptake of $\left[{ }^{3} \mathrm{H}\right] \mathrm{glycine}$ over $10 \mathrm{~min}$ at $37^{\circ} \mathrm{C}$ was measured in Medium M2-lactate or Medium $\mathrm{M} 2-\mathrm{Na}^{+}$with various $\left[{ }^{3} \mathrm{H}\right]$ glycine concentrations $(0.007-50 \mathrm{~mm} ; 0 \cdot 1-5 \mu \mathrm{Ci} / \mu \mathrm{l})$. Embryos of both stages were incubated together in the one droplet.

Collection and assay of uptake. At completion of incubation in radioactive medium, 6-10 embryos were removed and washed through 4 changes of $2 \mathrm{ml}$ ice-cold Medium M2 (4 min). Previous results established that minimal loss of $\left[{ }^{3} \mathrm{H}\right]$ glycine occurred through these procedures (Hobbs \& Kaye, 1985). Individual washed embryos were added to $200 \mu$ water and radioactivity was determined. Results are the means \pm s.d. of 2 experiments, each containing 6-10 embryos at each point. Embryos that did not appear normal $(<0.1 \%)$ when examined under the dissecting microscope at any stage of the experiment were discarded.

\section{Results}

\section{Glycine dependence of glycine uptake}

Glycine uptake by 2-cell embryos and blastocysts in the absence of $\mathrm{Na}^{+}$is linearly related to glycine concentration. The results are shown in Fig. 1(a) as a $\log -\log$ plot to show the relationship 
over a 10000 -fold concentration range. The equations to the lines fitted to the data by least squares linear regression were $v=0.803$ [gly] +0.567 for 2 cells (correlation coefficient, mean $v$ against [gly], 0.999) and $v=1.965$ [gly] +3.581 for blastocysts (correlation coefficient, 0.993) where units of $v$ are fmol $\mathrm{min}^{-1}$ embryo $^{-1}$ and of [gly] are mM.

To determine the dependence of glycine uptake on glycine concentration in the presence of $\mathrm{Na}^{+}$ the values for $\mathrm{Na}^{+}$-independent uptake were subtracted from those in the presence of $\mathrm{Na}^{+}$. The results are shown in Fig. 1(b) on a log-log scale, as above. The $\mathrm{Na}^{+}$-dependent uptake for embryos of both stages was saturable. Analysis of the data by non-linear regression analysis (Duggleby, 1984) provided the kinetic parameters in Table 1, which also includes the first-order rate constant for $\mathrm{Na}^{+}$-independent glycine uptake.

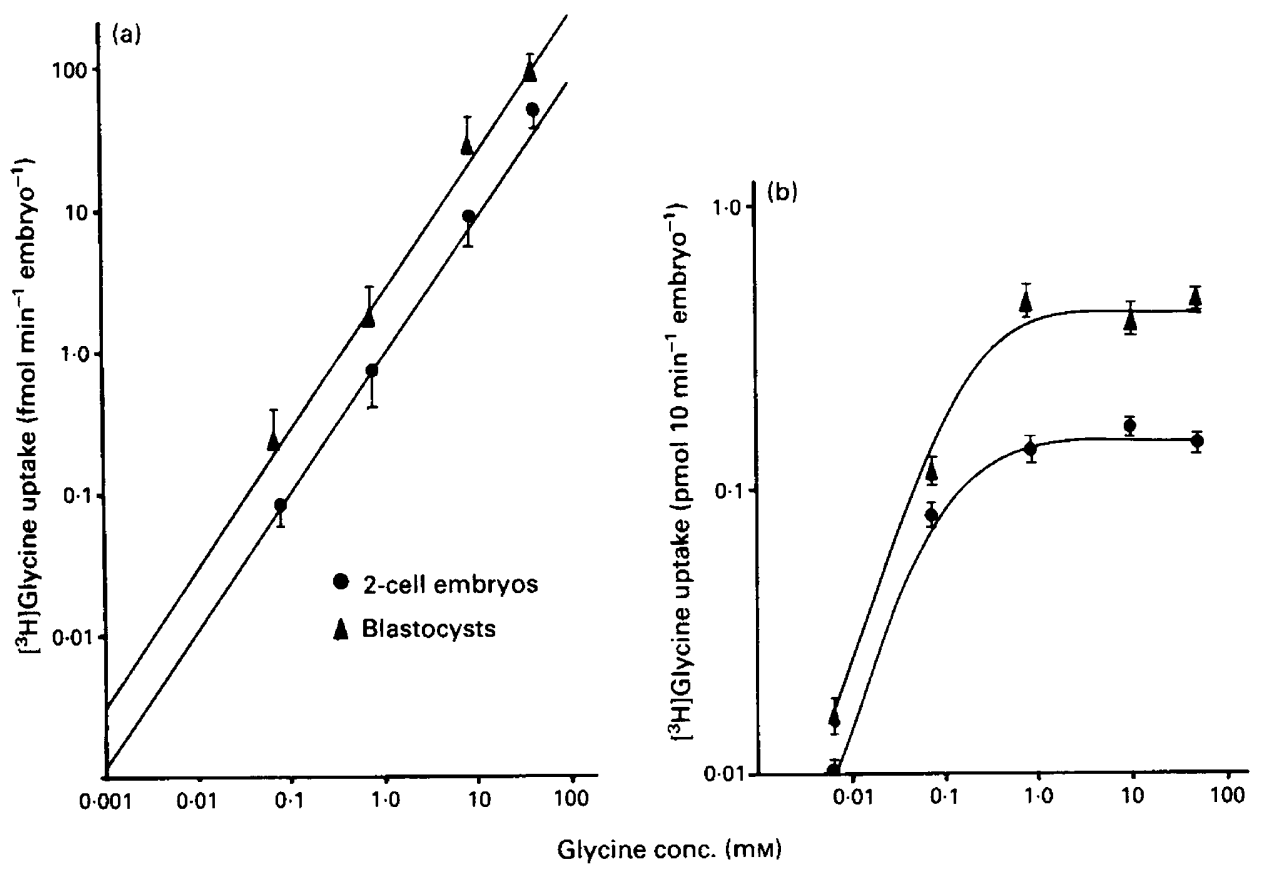

Fig. 1. Glycine dependence of $\left[{ }^{3} \mathrm{H}\right]$ glycine uptake by 2-cell and blastocyst-stage mouse embryos. (a) $\mathrm{Na}^{+}$-independent uptake; (b) $\mathrm{Na}^{+}$-dependent transport. Values are means \pm s.d. for 2 experiments, each comprised of at least 6 individual observations.

Table 1. Kinetic constants of glycine uptake in mouse embryos

\begin{tabular}{|c|c|c|c|}
\hline & $\begin{array}{l}K_{\mathrm{m}}^{*} \\
(\mu \mathrm{M})\end{array}$ & $\frac{V_{\max }^{*}}{\left(\mathrm{pmol} 10 \min ^{-1} \text { embryo }^{-1}\right)}$ & $\begin{array}{c}K_{\mathrm{o}}^{*} \\
\left(\mathrm{fmol} 10 \mathrm{~min}^{-1} \text { embryo }^{-1}\right. \\
\left.\mathrm{M}^{-1}\right)\end{array}$ \\
\hline 2-cell & $62 \pm 7$ & $0.157 \pm 0.004$ & $0.011 \pm 0.002$ \\
\hline Blastocyst & $274 \pm 134$ & $0.572 \pm 0.092$ & $0.019 \pm 0.003$ \\
\hline
\end{tabular}

* The $K_{\mathrm{m}}$ and $V_{\max }$ for $\mathrm{Na}^{+}$-dependent glycine uptake and $K_{\mathrm{o}}$, the first-order rate constant for $\mathrm{Na}^{+}$-independent glycine uptake, were determined by non-linear regression analysis of the results in Fig. 1. Confidence limits are standard errors. 


\section{$\mathrm{Na}^{+}$dependence of glycine uptake}

Measurements of $\left[{ }^{3} \mathrm{H}\right]$ glycine uptake at $1 \mathrm{~mm}$ were carried out at various $\mathrm{Na}^{+}$concentrations. The uptake rates are plotted in Fig. 2(a) as a function of the inverse of $\mathrm{Na}^{+}$concentration and in Fig. 2(b) as the inverse of the square of the $\mathrm{Na}^{+}$concentration. In 2-cell embryos and blastocysts the uptake rate was proportional to the inverse square of the $\mathrm{Na}^{+}$concentration but not the inverse. The lines fitted by least-squares linear regression were $v=195-0.478 v\left[\mathrm{Na}^{+}\right]^{-2}$ (correlation coefficient, -0.975 ) for 2-cell embryos, and $v=288-1.08 v\left[\mathrm{Na}^{+}\right]^{-2}$ (correlation coefficient, -0.951 ) for blastocysts, where units of $v$ are fmol $10 \mathrm{~min}^{-1}$ embryo ${ }^{-1}$ and of $\left[\mathrm{Na}^{+}\right]$are mM. This demonstrates that glycine uptake is dependent on co-transport of two $\mathrm{Na}^{+}$(Vidaver, 1964).
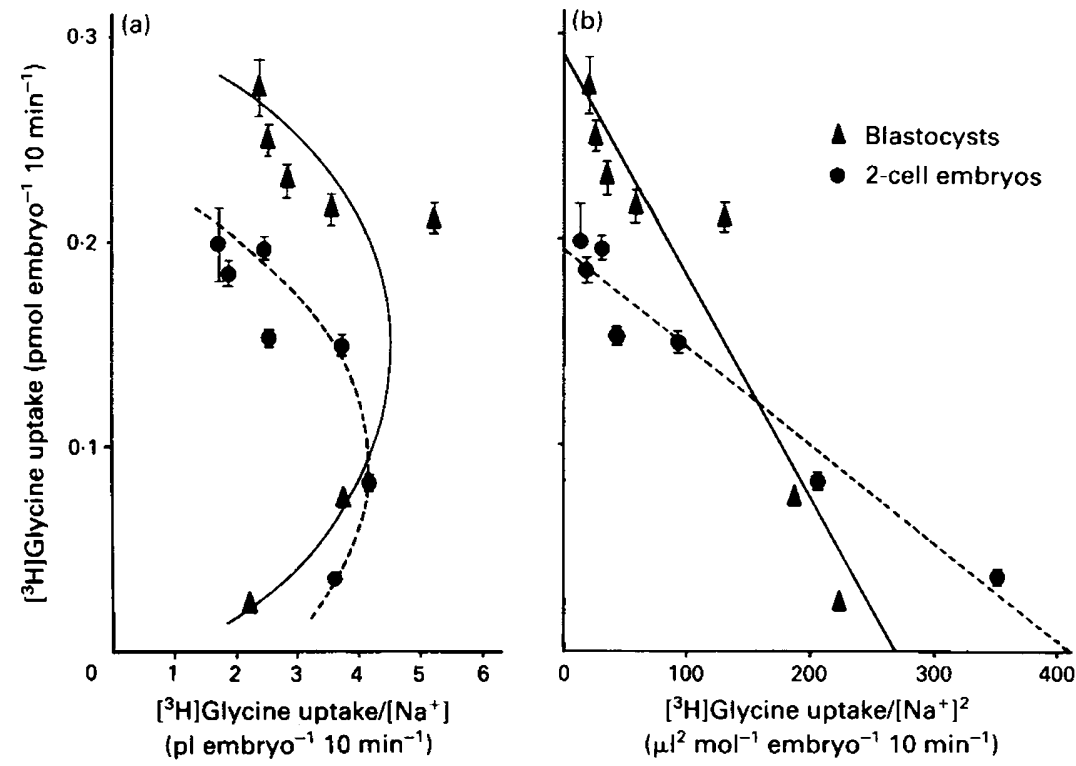

Fig. 2. $\mathrm{Na}^{+}$-dependence of $\left[{ }^{3} \mathrm{H}\right]$ glycine uptake by 2 -cell and blastocyst-stage mouse embryos. (a) Plotted as a function of $\left[\mathrm{Na}^{+}\right]^{-1}$; (b) plotted as a function of $\left[\mathrm{Na}^{+}\right]^{-2}$. Values are means \pm s.d. for 2 experiments, each comprised of at least 6 individual observations.

\section{Discussion}

To remove $\mathrm{Na}^{+}$completely from the incubation medium it was necessary to delete the sodium lactate. Because lactate is a key energy source for embryos, and amino acid uptake may require energy, it was necessary to ascertain that the absence of lactate did not affect glycine uptake in 2-cell embryos or blastocysts. This we confirmed, indicating that although glycine uptake is highly concentrative, under the brief conditions used here energy supplies are sufficient.

The results in Fig. 1 show that glycine uptake by embryos at both stages is by the combination of a non-saturable (at least up to $50 \mathrm{~mm}$-glycine) and a saturable route. The kinetic data show that, for the saturable system, $V_{\max }$ and $K_{m}$ change between the two stages, but provide no evidence for a second saturable glycine transport system in either stage. This result is consistent with our earlier observations (Hobbs \& Kaye, 1985) which demonstrated complex uptake kinetics in blastocysts. It now seems that the reason for this complexity is the presence of the $\mathrm{Na}^{+}$-independent nonsaturable uptake route. Non-saturable methionine uptake has been observed in rabbit (Miller \& 
Schultz, 1983) and mouse (Miller, 1984) embryos. The estimate of Miller (1984) of the rate constant for methionine uptake by mouse embryos was about twice the value we find for glycine. Our results do not indicate whether this non-saturable route involves diffusion or some other mechanism. However, it contributes little to the total uptake of glycine at concentrations below $10 \mathrm{~mm}$.

Glycine therefore appears to enter 2-cell embryos and blastocysts by one saturable route. We have already shown that in the 2-cell embryo this is the gly-system (Hobbs \& Kaye, 1985). At the time, the situation was not clear in the blastocyst but we suggested that the major route of entry was the A-system. The measurements of $\mathrm{Na}^{+}$-dependence were designed to determine the identity of the single saturable system operating for glycine uptake in blastocysts by making use of the unique dependence of the $g l y$-system on co-transport of two $\mathrm{Na}^{+}$(Vidaver, 1964; Christensen \& Handlogten, 1981). Since glycine uptake in the 2-cell embryo was via this system we compared $\mathrm{Na}^{+}$-dependence in 2-cell embryos and blastocysts. The results (Fig. 2) show that the system operating in 2-cell embryos and blastocysts requires co-transport of two $\mathrm{Na}^{+}$. However, earlier studies showed that alanine competes with glycine (Hobbs \& Kaye, 1985) and glycine with methionine for uptake by blastocysts (Kaye et al., 1982) and thus favoured transport of glycine by the A-system in blastocysts, which in other cells is not considered to co-transport $2 \mathrm{Na}^{+}$.

The solution to this puzzle is not yet clear. However, Jung, Schwarz \& Passow (1984) have reported a sodium-alanine co-transport system in toad (Xenopus laevis) oocytes with a Hill coefficient of 2 , i.e. the same as our observations for glycine transport in preimplantation mouse embryos. They conclude that this is an A-system. They too were unable to demonstrate inhibition by $N$-methylaminoisobutyric acid (MeAIB) as we also were previously unable to do (Hobbs \& Kaye, 1985).

The question therefore remains, where does the gly-system of the 2-cell embryo go? It may differentiate into the A-system. The present results support this view. Such a change might confer extra regulative properties on amino acid transport in embryos because of the susceptibility of the A-system to hormonal and adaptive regulation (Hobbs \& Kaye, 1985). Alternatively the gly-system may be predominantly sequestered inside the blastocyst by the formation of tight junctions during compaction, preventing its detection by the present techniques and leaving an A-like system co-transporting $2 \mathrm{Na}^{+}$in the abcoelic membranes. We are currently investigating this possibility.

The conclusion that glycine uptake results in the co-transport of $2 \mathrm{Na}^{+}$and that this co-transport persists into the blastocyst reveals a new route for the provision of intracellular $\mathrm{Na}^{+}$ for the juxtacoelic $\mathrm{Na}^{+}, \mathrm{K}^{+}$-ATPase sodium pumps. These pumps are proposed to be critical in $\mathrm{H}_{2} \mathrm{O}$ movement associated with blastocoele expansion. If the glycine concentration in mouse uterine fluid is the same as that in the rabbit (4-20 mM: Miller, 1984), then this could represent a significant $\mathrm{Na}^{+}$accumulation route.

We thank Dr Len Martin for critical manuscript review and our office staff for word processing. This work was supported by grants to P.L.K. from NHMRC (Australia) and University of Queensland Special Projects.

\section{References}

Benos, D., Biggers, J.D., Balaban, R.S., Mills, J.W. \& Overström, E.W. (1985) Developmental aspects of sodium-dependent transport processes of preimplantation rabbit embryos. In Regulation and Development of Membrane Transport Processes, pp. 211-235. Ed. J. S. Graves. John Wiley \& Sons, Inc., New York.

Borland, R.M. \& Tasca, R.J. (1974) Activation of a $\mathrm{Na}^{+}$-dependent aminoacid transport system in preimplantation mouse embryos. Devl Biol. 30, $169-182$.
Christensen, H.N. (1984) Organic ion transport during seven decades. The amino acids. Biochim. Biophys. Acta 779, 255-269.

Christensen, H.N. \& Handlogten, M.E. (1981) Role of system $G l y$ in glycine transport in monolayer cultures of liver cells. Biochem. Biophys. Res. Commun. 98, 102-107.

Colonna, R., Cecconi, S., Buccione, R. \& Mangia, F. (1983) Amino-acid transport systems in growing mouse oocytes. Cell Biol. Intl Rep. 7, 1007-1015.

DiZio, S.M. \& Tasca, R.J. (1977) Sodium dependent 
amino acid transport in preimplantation mouse embryos. Devl Biol. 59, 198-205.

Duggleby, R. (1984) Regression analysis of non-linear arrhenius plots: an empirical model and a computer program. Comput. Biol. Med. 14, 447-455.

Hobbs, J.G. \& Kaye, P.L. (1985) Glycine transport in mouse eggs and preimplantation embryos. J. Reprod. Fert. 74, 77-86.

Holmberg, S.R.M. \& Johnson, M.H. (1979) Amino acid transport in the unfertilized and fertilized mouse egg. J. Reprod. Fert. 56, 223-231.

Jung, D., Schwarz, W. \& Passow, H. (1984) Sodiumalanine co-transport in oocytes of Xenopus laevis: correlation of alanine and sodium fluxes with potential and current changes. J. Membrane Biol. 78, 29-34.
Kaye, P.L., Schultz, G.A., Johnson, M.H., Pratt, H.P.M. \& Church, R.B. (1982) Amino acid transport and exchange in preimplantation mouse embryos. $J$. Reprod. Fert. 65, 367-380.

Miller, J.G.O. (1984) Amino acid transport in preimplantation mammalian embryos. Ph.D. thesis, University of Calgary, Alberta.

Miller, J.G.O. \& Schultz, G.A. (1983) Properties of amino-acid transport in pre-implantation rabbit embryos. J. exp. Zool. 228, 511-525.

Vidaver, G.A. (1964) Transport of glycine by pigeon red cells. Biochemistry, N.Y. 3, 662-667.

Received 13 June 1985 